\title{
CUALIDADES Y DEFECTOS DE LOS PERUANOS: SU RELACIÓN CON LA HERENCIA COLONIAL
}

\author{
VIRTUES AND DEFECTS OF PERUVIANS COLONIAL HERITAGE \\ RAMÓN LEÓN ${ }^{1}$ \\ Universidad Ricardo Palma, Perú
}

(RECIBIDO El 25/10/2010, ACEPTADo el 26/11/2010)

\begin{abstract}
RESUMEN
En la presente comunicación se informa de un estudio llevado a cabo en 691 estudiantes ( $\mathrm{N}=691 ; 414$ mujeres y 277 hombres, con edades entre los 16 y 60 años de edad), a los que se solicitó que valoraran diez cualidades (trabajador, honesto, emprendedor, ambicioso, ahorrativo, solidario, creativo, ordenado, orgulloso y planificador) y diez defectos (flojo, corrupto, conformista, fatalista, gastador, individualista, pasivo, envidioso, acomplejado, hablador) del peruano promedio y, seguidamente, que valoraran cuán grande consideraban que era la influencia de la así llamada herencia colonial (los casi 400 años en que el Perú fue una colonia de España) en esas cualidades y defectos. Para el efecto, se utilizó una escala de 0 (muy bajo) a 4 (muy alto).
\end{abstract}

Los resultados dieron a conocer que los peruanos fueron vistos en materia de cualidades como creativos y trabajadores y, en lo que se refiere a defectos, como corruptos, acomplejados y envidiosos. Mientras que en lo concerniente a las cualidades la influencia de la herencia colonial no fue considerada como muy elevada, ésta sí se valoró como muy alta en lo que tenía que ver con los defectos de los peruanos.

Palabras claves: Cualidades, defectos peruanos, herencia colonial.

\begin{abstract}
This communication reports a study in 691 students (414 women, 277 men, 16-60 years old), who were asked to rate (on a scale of 0 to 4 ) ten virtues and ten defects of an average Peruvian. The virtues considered were hard-working, honest, enterprising, ambitious, thrifty, sympathetic, creative, tidy, proud, and wel.organized; the defects were lazy, corrupt, conformist, fatalist, spendthrift, individualist, passive, envious, inhibited, talkative. They were asked too to rate the influence of colonial Spanish heritage on these virtues and defects (0 to 4$)$.

The average Peruvians were seen as creative and har.working, but in reference to the defects as corrupt, inhibited and envious. The influence of colonial Spanish heritage on the virtues was evaluated as not so high, but it was perceived as high in reference to defects.
\end{abstract}

Keywords: Virtues and defects of peruvians, colonial heritag.

1 Profesor Principal de la Facultad de Psicología de la URP. E-mail: rld310850@yahoo.com.mx 


\section{INTRODUCCIÓN}

¿Quiénes somos? Esta es una interrogante presente entre los peruanos ya desde el Inca Garcilaso de la Vega con sus Comentarios Reales (Inca Garcilaso de la Vega 16091617/2007), hace cuatro siglos, hasta nuestros días. Cuatrocientos años de reflexión que, en lugar de ofrecer respuestas, han terminado planteando preguntas cada vez más inquietantes, dado que tras ignorar por mucho tiempo su gran heterogeneidad cultural, la sociedad peruana comienza paulatinamente a reconocer su diversidad étnica (Agenda: Peru, 2000). Un libro, entre tanto clásico moderno de la antropología peruana, tiene por título No hay país más diverso (Degregori, 2000).

Eso ha dado nuevos estímulos para la reflexión, aunque Fuenzalida (2009) cree reconocer un relegamiento de la discusión acerca de la identidad de los peruanos que "... no procede, sin embargo, de la emergencia final, más allá de las polémicas, de un consenso intelectual acerca de la naturaleza de nuestra identidad como nación o como pueblo, sino más bien de un agotamiento de los términos en que la cuestión ha venido siendo discutida" (p. 208).

Lo cierto es que el tema de la identidad de los peruanos ha sido abordado desde los ángulos más variados, como el étnico (Valcárcel, 1945/1965) y el religioso (Belaúnde, 1931/1991) pasando por el literario (De la Riva Agüero y Osma 1905/2008), así como desde el marxismo (Mariátegui, 1928/1992) hasta el enfoque interdisciplinario (De Althaus, 1979).

En la presente comunicación se informa de un estudio psicométrico efectuado en universitarios acerca de un aspecto tratado en la mayoría de las discusiones acerca de la identidad nacional. Nos referimos a las virtudes y defectos de los peruanos, relacionándolos con la herencia colonial presente en la historia del Perú.

Virtudes y defectos (pero, en especial las primeras) han cobrado gran importancia como tema de estudio de la psicología contemporánea, a partir del desarrollo de la psicología positiva (Alarcón, 2009), dejando de ser tema exclusivo de la ética para ser admitidos en la reflexión psicológica, e inclusive, ser abordados desde una perspectiva experimental o psicométrica (Milgram, 1980; Pury \& López, 2010) o cuasi experimental (Zimbardo, 2008). Martin Seligman, uno de los más destacados teóricos de este enfoque ha propuesto una clasificación de ellas relievando su importancia para una vida con sentido (Seligman \& Peterson, 2007).

Fuera del ámbito de la psicología, en el contexto latinoamericano la discusión sobre el particular ha sido muy frecuente (Valderrama, 1986): se puede encontrar ensayos o estudios acerca de las cualidades y defectos de argentinos (D'Adamo \& García Beaudoux, 1995; Aguinis, 2005), chilenos (García Huidobro \& M.Auliffe, 1998; Larraín, 2001), uruguayos (Benedetti, 1960), bolivianos (Arguedas, 1937), paraguayos (Vera, 1996; Domínguez, 2009) y ecuatorianos (Espinosa Tamayo, 1979) para mencionar solo algunos casos.

\section{La identidad nacional}

El concepto de identidad cobra fuerza en la psicología a partir de los trabajos de Erik H. Erikson, destacando lo que él denominó "el sentido de mismidad y de continuidad como individuo" (Erikson, 1976; 1994; p. 600). 
Gracias a este autor el concepto comienza a circular en las ciencias sociales, y prontamente -como sucede con muchos conceptos psicológicos inicialmente propuestos para designar rasgos individuales- se extiende a la comprensión de los pueblos, llegando a hablarse de la identidad nacional (Smith, 1997; Habermas, 1989; Bloom, 1993) y diversificándose.

Es debido a ese proceso de diversificación que, en el caso de América Latina, hay quienes lo identifican con lo autóctono, en tanto que otros lo vinculan con lo campesin.mestizo, o con lo referido a las poblaciones indígenas o con los urban.subdesarrollados (Devés Valdés, 2005).

Al margen de la psicología académica, por cierto, científicos sociales y pensadores han reflexionado en diferentes épocas sobre las características distintivas de sus respectivos pueblos: tal el caso de Karl Jaspers sobre la cuestión de la responsabilidad de Alemania en la Segunda Guerra Mundial (Jaspers, 1998); tal también el de Angel Ganivet con sus ideas acerca de España después de la debacle de 1898 (Ganivet, 1990); tal, por último, para solo mencionar dos ejemplos provenientes de América Latina, la visión profundamente sombría de Alcides Arguedas acerca de su país, Bolivia, en su obra Pueblo enfermo (Arguedas, 1937), y la fascinante reflexión que formula Octavio Paz en El laberinto de la soledad (Paz, 1990).

La reflexión psicológica y sociológica acerca de la identidad nacional ha dado lugar a una literatura de dimensiones casi inconmensurables (e. g. Arenas, 2003; Breitinger \& Sander, 1986; Faltin \& Wright, 2007; Herrmann et al., 2004; Joseph, 2004; Montes Garcés, 2007; Sánchez Martínez, 1997, Theis.Morse, 2009; Woodward, 2000), pero está lejos de haber agotado el tema. Por el contrario, la importancia del concepto de identidad nacional se ha tornado mayor en estas décadas caracterizadas por el indetenible proceso de globalización. Esta, con su tendencia uniformizadora y con la difusión de patrones universales de comportamiento, gustos y formas de pensar, pero también con el debilitamiento del estado-nación con respecto a los movimientos de capitales (Friedman, 2007), es percibida muchas veces como una amenaza a la identidad de los pueblos, como ocurre por ejemplo en Bolivia, Ecuador, y más recientemente en Chile, países en los cuales minorías étnicas experimentan el temor de que sus tradiciones, sus usos y costumbres desaparezcan (Chua 2003, Mayorga \& Córdova 2008).

Como lo señala Larraín (1996; p. 66), "las grandes transformaciones sociales traídas por la globalización tienden a desarraigar identidades culturales ampliamente compartidas y, por lo tanto, alteran las categorías en términos de las cuales los sujetos construían sus identidades".

En el Perú, como hemos señalado, numerosas obras tratan el tema de la identidad nacional (e. g. Mariátegui, 1928/1992; Basadre, 1931/1987; Matos Mar, 1987; Flores Galindo, 1994; Salgado Lévano, 1999), dedicando una amplia reflexión a un concepto central a la hora de comprender las vicisitudes de la historia peruana: el de herencia colonial.

La herencia colonial es un concepto de límites no siempre precisos. En el marco de este trabajo por herencia colonial entendemos la influencia que siguen ejerciendo los años de dominación española (es decir el largo periodo que se conoce como la Colonia en el Perú) en los patrones de dependencia económica, en la persistencia de instituciones coloniales, 
así como en la mentalidad y la conducta de los latinoamericanos (Dealy, 1968; Haber, 1997; Adelman, 1999).

El periodo de la Colonia, así como el que lo antecedió, el de la Conquista (que trae como consecuencia el derrumbe del Imperio Incaico y la imposición violenta de normas, conductas y creencias hasta ese momento ajenas), son percibidos como una violenta irrupción en la historia del pueblo peruano, que ha dejado no solo una visión traumática de los hechos, sino también ha enraizado entre los peruanos formas de pensar y de actuar, y de verse a sí mismos, que aún hoy ejercen gran influencia grande en la vida cotidiana y que son percibidos como un decisivo elemento de explicación del atraso del país.

Ciertamente, la atribución del subdesarrollo de un pueblo a la violenta presencia de potencias foráneas en su historia no solo ocurre en el Perú ni tampoco exclusivamente entre los países otrora colonizados por España. En países como Argelia y el Congo, para citar un par de casos, es extendida asimismo la acusación a las metrópolis francesa y belga respectivamente de ser las causantes del caos y el atraso reinantes (Clark, 2002; McDougall, 2006; Horne, 2006).

Volviendo al Perú, es frecuente escuchar que la gran causa de nuestros problemas es el predominio de España desde el siglo XVI hasta comienzos del siglo XIX: los años de la Colonia y la Conquista son presentados como hechos brutales, cuyas consecuencias aún se dejan sentir en la realidad social del país (Manrique, 1993). León et al. (2008) escriben que "es de observación frecuente la presencia de afirmaciones por parte de ciudadanos acerca de la influencia de España y de los supuestos rasgos caracterológicos de los conquistadores en el modo de ser de los peruanos" (p. 88).

La Colonia despierta entre los peruanos sentimientos ambiguos. Ricardo Palma, el autor de las celebradas Tradiciones Peruanas, presenta una imagen "rosada" de ese periodo, si bien interlineas puede percibirse la visión escéptica de esos trescientos años y de la mayoría de sus protagonistas de primera y segunda línea (Palma, 1996).

Nada menos que José Carlos Mariátegui era del parecer que "el amor al virreinato le parece a nuestra gente un sentimiento distinguido, aristocrático, elegante. Los balcones moriscos, las escalas de seda, las 'tapadas' y otras tonterías, adquieren ante sus ojos un encanto, un prestigio, una seducción exquisitos. Una literatura decadente, artificiosa, se ha complacido en añorar, con inefable y huachafa ternura, ese pasado postizo y mediocre" (citado por Obando Morán, 2009; p. 144).

De otro lado, Manuel González Prada, el intelectual peruano más importante de la década y media final del siglo XIX, no tiene reparos en ejercer una ácida crítica a esa época, presentándola en buena medida como la causa de muchas de las deficiencias y miserias del Perú Republicano (véase González Prada, 2009).

Ese sentimiento antihispano ha convivido, sin embargo, con la presencia y la acción de un grupo de distinguidos intelectuales que, por el contrario, han destacado y promovido los lazos que unen al Perú con España. Uno de los más activos sobre el particular fue Honorio Delgado, destacado psiquiatra peruano, autor -entre otros trabajos- de un artículo titulado "Fundamento hispánico de nuestra unidad cultural", incluido en su obra De la cultura y sus artífices (Delgado, 1961/2001). 
En los últimos años los sentimientos antiespañoles han ganado renovada actualidad a partir de las inversiones considerables de muchas empresas españolas en América Latina, una región vista como culturalmente cercana a España (Baklanoff, 1996). Su presencia no siempre ha sido vista con agrado, ciertamente.

Así, Telefónica, transnacional española que tiene un control casi monopólico de las telecomunicaciones en el Perú, ha estado envuelta en muchas ocasiones en protestas acerca de la calidad del servicio, el trato dispensado al cliente y a los costos que deben pagar los usuarios, todo lo cual ha ido acompañado de referencias al pasado de explotación hispana durante la Colonia, por parte de los que protestaban.

Sin embargo, cuando los peruanos piensan en la emigración, España es uno de los destinos preferidos, y, en las clases más pudientes del Perú se puede reconocer la inclinación a conservar tradiciones de reconocido influjo ibérico: las corridas de toros, por ejemplo.

Todo esto configura algo así como una ambivalencia afectiva de muchos de los integrantes de la sociedad peruana hacia España y a la herencia dejada por ella.

Según Montoya (1992), la imagen negativa del peruano se caracteriza por cinco rasgos: (1) ser ociosos; (2) ser proclives al derroche y tener poca disposición para el ahorro; (3) ser incumplidos; (4) no hacer valer nuestros derechos; y, (5) preferir lo extranjero a lo peruano. De acuerdo con este autor las cuatro primeras características son vistas como la herencia colonial o española.

En contraposición a esta imagen negativa de la Conquista y la Colonia y de los españoles en la historia del país, está la visión idealizada del Incanato y de las etapas prehispánicas.

Las referencias a un pasado prehispánico glorioso son frecuentes en el Perú. Silverman (2002) anota que el "estad.nación peruano [...] ha dirigido con frecuencia su mirada al pasado remoto en la discusión de políticas y cuestiones trascendentales acerca de su presente y de su futuro" (p. 882), señalando, a guisa de demostración de esto, varios ejemplos, entre los cuales está la adopción de un águila al estilo de la cultura preincaica Chavín como emblema al momento de su fundación por parte del Partido Aprista Peruano, en una época en la cual esa cultura era vista como la "madre" de todas; las referencias al pasado incaico por parte de Alejandro Toledo y la selección del nombre "Chavín de Huantar" por parte del Ejército Peruano en la operación militar de rescate de los rehenes en la Embajada de Japón en el Perú en 1996.

Estudiar lo que piensan los peruanos acerca de la herencia colonial y sus consecuencias en nuestro modo de ser y en la sociedad peruana fue el objetivo del presente trabajo, motivado por la cercanía del bicentenario de la independencia de muchos de los países latinoamericanos (incluido el Perú), que viene dando lugar a una serie de obras y estudios que analizan no solo la gesta independentista, sino también los orígenes y las consecuencias de los muchos años de dominación española (e.g. Restall, 2004; Rojas, 2009; Palacios, 2009; Chust \& Frasquet, 2009; Goytisolo, 2010; Lucena Giraldo, 2010).

El estudio se concentró en la valoración de un conjunto de cualidades y defectos que suelen ser considerados como los más característicos de los peruanos (ser creativo y ser envidioso, por ejemplo), y en la atribución del origen de ellos a la herencia colonial o española. 


\section{Método}

Se elaboró dos reactivos que fueron aplicados a una muestra de 691 universitarios residentes en Lima (414 mujeres y 277 hombres, en edades entre los 16 y 60 años de edad, si bien el $81,9 \%$ se encontraba entre los 16 y 25 años).

Los reactivos solicitaban la valoración de características positivas y negativas atribuidas al peruano promedio. El primero solicitaba que se valorara en una escala de 0 (muy bajo) a 4 (muy alto) diez cualidades (trabajador, honesto, emprendedor, ambicioso, ahorrativo, solidario, creativo, ordenado, orgulloso y planificador). El segundo solicitaba que se valorara diez defectos (flojo, corrupto, conformista, fatalista, gastador, individualista, pasivo, envidioso, acomplejado, hablador) del peruano promedio.

Se solicitaba asimismo que se valorara la supuesta influencia de la herencia española o colonial en cada una de las cualidades y los defectos antes mencionados, utilizando igualmente una escala de 0 (muy bajo) a 4 (muy alto).

El apéndice presenta las diez cualidades y los diez defectos antes mencionados, así como la escala de valoración de cada uno de ellos y de la influencia hispana.

\section{RESULTADOS}

La Tabla 1 presenta las propiedades psicométricas del reactivo que contenía la relación de cualidades del peruano promedio.

Tabla N. ${ }^{\circ}$ 1. Propiedades psicométricas de la relación de características positivas del peruano promedio.

\begin{tabular}{lccc}
\hline Cualidades del peruano promedio & $\mathrm{M}$ & $\mathrm{r}$ & Alfa total si se retira el ítem \\
\hline Trabajador & 2,44 &, 46 &, 75 \\
Honesto & 1,60 &, 50 &, 75 \\
Emprendedor & 2,47 &, 60 &, 73 \\
Ambicioso & 2,39 &, 30 &, 73 \\
Ahorrativo & 1,80 &, 40 &, 76 \\
Solidario & 2,24 &, 45 &, 75 \\
Creativo & 3,09 &, 38 &, 76 \\
Ordenado & 1,67 &, 43 &, 75 \\
Orgulloso & 2,29 &, 43 &, 76 \\
Planificador & 1,73 &, 47 &, 75 \\
\hline
\end{tabular}

Alfa: ,77

Las correlaciones íte.total de la relación de las características positivas, como puede verse, estuvieron entre ,30 y ,60, y el alfa fue elevado $(, 77)$. 
La cualidad más valorada en los peruanos promedio fue creativo $(3,09)$, seguida por emprendedor $(2,47)$, trabajador $(2,44)$, ambicioso $(2,39)$ y orgulloso $(2,29)$. Los promedios más bajos correspondieron a honesto $(1,60)$, ordenado $(1,67)$ y planificador $(1,73)$.

Sometidos los resultados al análisis factorial (análisis de componentes principales) se obtuvo los resultados que se presentan en la Tabla 2 .

Tabla N. ${ }^{\circ}$ 2. Estructura factorial de la relación de características positivas de los peruanos promedio.

\begin{tabular}{lccc}
\hline \multicolumn{1}{c}{ Cualidad } & Factor I & Factor II & Factor III \\
\hline Trabajador & &, 74 & \\
Honesto &, 66 &, 31 & \\
Emprendedor & &, 61 &, 33 \\
Ambicioso & & &, 86 \\
Ahorrativo &, 63 & & \\
Solidario &, 46 &, 53 & \\
Creativo & &, 75 & \\
Ordenado &, 73 & & \\
Orgulloso & & &, 66 \\
Planificador & & &, 38 \\
Eigenvalue & 2,20 & 2,05 & 1,53 \\
\% varianza explicado & 22,05 & 20,4 & 15,32 \\
\hline
\end{tabular}

Se halló tres factores que explicaron el 57,91\% de la varianza. El primero fue Honestidad $y$ orden, con 4 ítems, con cualidades en que los promedios fueron los más bajos (el promedio total fue $\mathrm{M}=1,97$ ). El segundo fue Laboriosidad (con 5 ítems; $\mathrm{M}=2,36$ ); $\mathrm{y}$, el tercero, Conductas proactivas (con 4 ítems; $\mathrm{M}=2,22$ ).

Veamos seguidamente cómo valoraron los sujetos el aporte de la herencia colonial o española a estas características positivas. Primero examinaremos las propiedades psicométricas encontradas.

La Tabla 3 presenta los resultados sobre el particular. 
Tabla $\mathbf{N}^{\circ}$ 3. Propiedades psicométricas de la relación que evalúa la influencia de España en las características positivas de los peruanos promedio.

\begin{tabular}{lccc}
\hline $\begin{array}{c}\text { Se debe a la herencia } \\
\text { española o colonial }\end{array}$ & $\mathrm{M}$ & $\mathrm{r}$ & $\begin{array}{c}\text { Alfa total si se } \\
\text { retira el ítem }\end{array}$ \\
\hline Trabajador & 1,60 &, 54 &, 86 \\
Honesto & 1,67 &, 59 &, 85 \\
Emprendedor & 1,67 &, 62 &, 85 \\
Ambicioso & 2,49 &, 43 &, 87 \\
Ahorrativo & 1,72 &, 64 &, 85 \\
Solidario & 1,46 &, 59 &, 85 \\
Creativo & 1,52 &, 58 &, 85 \\
Ordenado & 1,72 &, 66 &, 85 \\
Orgulloso & 2,26 &, 57 &, 86 \\
Planificador & 1,73 &, 66 &, 85 \\
\hline
\end{tabular}

Alfa: , 87

Las correlaciones ítem-total fueron de ,43 a ,66, y el alfa fue ,87. Los promedios más elevados fueron los de ambicioso $(2,49)$ y orgulloso $(2,26)$. Los más bajos, los de solidario $(1,46)$ y creativo $(1,52)$.

La Tabla 4 presenta las características psicométricas de la relación de los defectos de los peruanos.

Tabla N. ${ }^{\circ}$ 4. Propiedades psicométricas de la relación de las características negativas de los peruanos promedio.

\begin{tabular}{lccc}
\hline $\begin{array}{c}\text { Defectos del peruano } \\
\text { promedio }\end{array}$ & $\mathrm{M}$ & $\mathrm{r}$ & $\begin{array}{c}\text { Alfa total si se } \\
\text { retira el item }\end{array}$ \\
\hline Flojo & 2,42 &, 44 &, 70 \\
Corrupto & 2,93 &, 28 &, 76 \\
Conformista & 2,80 &, 53 &, 69 \\
Fatalista & 2,40 &, 47 &, 70 \\
Gastador & 2,68 &, 42 &, 70 \\
Individualista & 2,55 &, 43 &, 70 \\
Pasivo & 2,26 &, 29 &, 72 \\
Envidioso & 2,84 &, 56 & .69 \\
Acomplejado & 2,96 &, 49 &, 69 \\
Hablador & 2,77 &, 23 &, 73 \\
\hline
\end{tabular}

Alfa: , 73 
Las correlaciones ítem-total fueron desde muy bajas (hablador: ,23 y flojo: ,28) hasta moderadas (envidioso; ,56). El alfa fue elevado (,73).

Los promedios más elevados los obtuvieron acomplejado $(2,96)$, corrupto $(2,93)$ y envidioso $(2,84)$. Los promedios más bajos correspondieron a pasivo $(2,26)$, fatalista $(2,40)$ y flojo $(2,42)$

La Tabla 5 da a conocer la estructura factorial (análisis de componentes principales) de la relación.

Tabla N. ${ }^{\circ}$ 5. Estructura factorial de la relación de características negativas de los peruanos promedio.

\begin{tabular}{lcc}
\hline & Factor I & Factor II \\
\hline Flojo &, 57 & \\
Corrupto & & \\
Conformista &, 62 &, 32 \\
Fatalista &, 66 & \\
Gastador &, 36 &, 47 \\
Individualista &, 54 & \\
Pasivo &, 66 & \\
Envidioso &, 41 &, 62 \\
Acomplejado &, 37 &, 59 \\
Hablador & &, 80 \\
Eigenvalue & 2,47 & 1,98 \\
\% varianza explic. & 24,7 & 19,8 \\
\hline
\end{tabular}

Se identificó dos factores, que explicaron el 44,5\% de la varianza. Uno, con 8 ítems, Conformismo, caracterizado por escasa iniciativa, y poca capacidad para cambiar los hechos $(\mathrm{M}=2,61)$. El otro, Acomplejamiento, en el cual se encuentran los ítems conformista, hablador, envidioso, acomplejado y gastador $(\mathrm{M}=2,81)$.

La Tabla 6 presenta las características psicométricas de la influencia colonial o hispana en los defectos de los peruanos promedio. 
Tabla N. ${ }^{\circ}$ 6. Propiedades psicométricas de la evaluación de la influencia de España en los defectos de los peruanos promedio.

\begin{tabular}{lccc}
\hline $\begin{array}{c}\text { Se debe a la herencia } \\
\text { colonial o española }\end{array}$ & M & r & $\begin{array}{c}\text { Alfa total si se retira } \\
\text { el ítem }\end{array}$ \\
\hline Flojo & 2,48 &, 62 &, 88 \\
Corrupto & 2,78 &, 69 &, 88 \\
Conformista & 2,49 &, 70 &, 88 \\
Fatalista & 2,40 &, 47 &, 70 \\
Gastador & 2,32 &, 67 &, 88 \\
Individualista & 2,39 &, 64 &, 83 \\
Pasivo & 2,22 &, 54 &, 89 \\
Envidioso & 2,67 &, 74 &, 87 \\
Acomplejado & 2,68 &, 58 &, 88 \\
Hablador & 2,17 &, 51 &, 89 \\
\hline
\end{tabular}

Alfa: , 89

A diferencia de lo sucedido en el caso anterior, las correlaciones íte.total fueron más homogéneas (de ,51 a ,74), y el alfa elevado (,89).

Para los integrantes de la muestra, la mayor influencia de la herencia colonial en nuestros defectos se expresó sobre todo en corrupto $(2,78)$, acomplejado $(2,68)$ y envidioso $(2,67)$, mientras que el puntaje menor fue en el de pasivo $(2,22)$.

La Tabla 7 integra los resultados de las escalas previas y los presenta en el orden en el cual fueron valorados, tanto las cualidades como los defectos.

Tabla N. ${ }^{\circ}$ 7. Promedios de las cualidades y defectos atribuidos a los peruanos, así como de la influencia hispana en unas y en otros.

\begin{tabular}{lccccc}
\hline \multicolumn{1}{c}{$\begin{array}{c}\text { Cualidad de } \\
\text { peruanos promedio }\end{array}$} & Valoración & $\begin{array}{c}\text { Valoración de la } \\
\text { influencia colonial o } \\
\text { hispana }\end{array}$ & $\begin{array}{c}\text { Defecto de } \\
\text { peruanos promedio }\end{array}$ & $\begin{array}{c}\text { Valoración de la } \\
\text { Valoración }\end{array}$ & $\begin{array}{c}\text { influencia colonial } \\
\text { o hispana }\end{array}$ \\
\hline Creativo & 3,09 & 1,52 & Acomplejado & 2,96 & 2,68 \\
Emprendedor & 2,47 & 1,67 & Corrupto & 2,93 & 2,78 \\
Trabajador & 2,44 & 1,60 & Envidioso & 2,84 & 2,67 \\
Ambicioso & 2,39 & 2,49 & Conformista & 2,80 & 2,49 \\
Orgulloso & 2,29 & 2,26 & Hablador & 2,77 & 2,17 \\
Solidario & 2,24 & 1,46 & Gastador & 2,68 & 2,43 \\
Ahorrativo & 1,80 & 1,72 & Individualista & 2,55 & 2,39 \\
Planificador & 1,73 & 1,73 & Flojo & 2,42 & 2,48 \\
Ordenado & 1,67 & 1,72 & Fatalista & 2,40 & 2,32 \\
Honesto & 1,60 & 1,67 & Pasivo & 2,26 & 2,22 \\
\hline
\end{tabular}

Escala de valoración: 0 = muy bajo; 1 = bajo; 2 = normal; 3 = alto; 4 = muy alto. 
Las cualidades que ocuparon los tres primeros lugares fueron creativo, emprendedor y trabajador. Ambicioso se ubicó en el cuarto lugar y orgulloso en el quinto. Honesto ocupa el último lugar.

Entre los defectos los tres que obtuvieron los promedios más altos fueron acomplejado, corrupto y envidioso, seguidos de conformista.

\section{DISCUSIÓN}

\section{Cualidades}

Desde hace algunos años se comenta con entusiasmo el crecimiento económico que el Perú experimenta (León, 2008), destacando algunas cualidades de los peruanos: creativos, trabajadores, tenaces, esforzados (véase por ejemplo Crabtree, 2004). En particular, se habla mucho de la gastronomía como una de las expresiones más acusadas de la creatividad de los peruanos (Espinosa \& Calderón Prada, 2009).

Los integrantes de la muestra reconocieron esos potenciales creativos, así como la laboriosidad e iniciativa de sus compatriotas al considerar esas tres cualidades como las más destacadas de las diez enumeradas en este estudio, si bien la de creativo fue considerada como alta, y las de emprendedor y trabajador como normales. En cuarto lugar ubicaron a la cualidad de ambicioso, que guarda relación con las tres anteriores.

Sin embargo, cuatro cualidades decisivas en el mundo moderno (ahorro, orden, planificación y honestidad; vide Peyrefitte, 1996; Porter, 1996 y Hacking, 2006) fueron valoradas como muy bajas. En las cuatro cualidades agrupadas en el factor 1, honesto, ahorrativo, solidario y ordenado, los promedios obtenidos fueron bajos en comparación con los de las otras cualidades.

En particular, destaca el hecho de que la honestidad fuera la que obtuviera el más bajo de todos los promedios, tanto en el ítem pertinente (honesto) como también en el del factor I (Honestidad y orden).

La influencia hispana en la cualidad creativo obtuvo una valoración baja $(1,52)$, y solo fue menor la que se valoró para la cualidad solidario $(1,46)$. Las más altas valoraciones de la influencia colonial o hispana estuvieron referidas a ambicioso $(2,49)$ y orgulloso $(2,26)$, dos rasgos que suelen ser atribuidos históricamente a los españoles (Manrique 1993). La influencia hispana en las cualidades de emprendedor y trabajador, atribuidas a los peruanos, fue valorada como baja en general (1,67 y 1,60, respectivamente).

\section{Defectos}

Como puede verse, acomplejado (2,96, normal pero muy cerca a alto) ocupó el primer lugar, seguido de corrupto $(2,93)$ y envidioso $(2,84)$.

Se trata de adjetivos que aluden a desarrollos individuales frustrados, a conductas sinuosas. Los tres configuran la imagen de los peruanos como un pueblo en el cual el apocamiento, el resentimiento y la tendencia a mirar con envidia al otro son experiencias 
frecuentes: "la tríada corrupto, envidioso y acomplejado, ofrece una imagen muy pobre de los peruanos: una imagen de desconfianza, recelo y malas intenciones, así como escasa capacidad para afirmarse como personas" (León et al., 2008; p. 175).

Es llamativa la concordancia que existe entre el último lugar que ocupa la honestidad entre las cualidades de los peruanos y la valoración de la corrupción entre sus defectos más pronunciados.

Estos resultados confirman la elevada percepción que se tiene de la corrupción como un fenómeno sumamente frecuente en la sociedad peruana (e. g. Salgado, 1999; Quiroz, 2008).

La valoración de envidioso como el tercer defecto que obtiene el más alto promedio remite a la percepción generalizada de que hay mucha envidia en la sociedad peruana (e.g. Rotondo et al., 1963; León, 2002; León \& Martell, 1994; León \& Moscoso, 1991; León et al., 2003).

Esto probablemente explica la profunda desconfianza interpersonal que hay en el Perú. En un reciente estudio llevado a cabo en Argentina, Brasil, Chile, Colombia, Guatemala, México y Perú, los porcentajes de baja confianza social en el Perú (71\%) fueron los más elevados después de los de Brasil (86\%) (Valenzuela, 2008).

En lo que se refiere a los resultados en corrupto y acomplejado, éstos guardan asimismo semejanza con los obtenidos en la reciente encuesta sobre percepción de la corrupción realizado por el Instituto de Opinión Pública de la Pontificia Universidad Católica del Perú (2009) y con los de un trabajo previo llevado a cabo por el autor (León, 2009) en el cual se indagó acerca de la valoración que las personas hacían del nivel de honestidad y de la autoestima de los peruanos. En la tabla que sigue se presenta los resultados según las tres variables con las cuales se trabajó en ese estudio: la de género, la de clase social autoasignada y la de raza autoasignada.

Tabla N. ${ }^{\circ}$ 8. Valoración del nivel de honradez y de la autoestima de los peruanos en el estudio de León (2009).

\begin{tabular}{ccccccccccc}
\hline & Hombres & Mujeres & $\begin{array}{c}\text { Clase } \\
\text { alta }\end{array}$ & $\begin{array}{c}\text { Clase } \\
\text { media }\end{array}$ & $\begin{array}{c}\text { Clase } \\
\text { baja }\end{array}$ & Blancos & Mestizos & Andinos & Negros & Orientales \\
\hline NHP & 1,24 & 1,20 & 1,16 & 1,23 & 1,15 & 1,17 & 1,23 & 1,44 & 1,00 & 1,36 \\
AEP & 1,56 & 1,52 & 1,33 & 1,54 & 1,70 & 1,49 & 1,55 & 1,74 & 1,45 & 1,66 \\
\hline
\end{tabular}

Leyenda: NHP $=$ Nivel de honradez de los peruanos; AEP $=$ Autoestima de los peruanos Escala de calificación: $0=$ muy bajo; $1=$ bajo; $2=$ regular; $3=$ alto; $4=$ muy alto

Nota. La muestra estuvo conformada por 1373 universitarios $[$ Hombres $=716$; Mujeres $=657$. Estas personas se autoclasificaron en cuanto a nivel socioeconómico de la siguiente forma: Clase alta= 30; Clase media= 1271; Clase baja = 64. En lo que concierne a raza la autoclasificación arrojó los siguientes resultados: Blancos= 381; Mestizos = 889; Andinos = 27; Negros = 22; Orientales = 33].

Puede observarse que en ningún caso los promedios de valoración de la honestidad y de la autoestima de los peruanos llegaron a 2 (regular). En el caso de la honestidad los promedios siempre fueron los más bajos. 
Volviendo a los resultados obtenidos en este estudio, la mayor influencia hispana en materia de defectos de los peruanos fue la atribuida a la corrupción $(2,78)$, seguida por la atribuida a los otros defectos más pronunciados de los peruanos en la percepción de la muestra (2,68 para acomplejado, y 2,67 para envidioso).

Esa influencia puede remitirse a la imagen que ha quedado de los conquistadores, vistos como gente sin mayor cultura, pero sobre todo como una banda de aventureros, casi delincuentes (León, 2010).

Un hecho que merece destacarse es que los encuestados atribuyeron una menor influencia de la herencia colonial en las cualidades $(M=1,72)$, mientras que concedieron una importancia mayor a dicha herencia a la hora de calificarla con respecto a los defectos de sus connacionales $(\mathrm{M}=2,46)$.

La mayor valoración de la influencia de la herencia colonial en los defectos de sociedades que han sido colonizadas no solo ocurre en el Perú: es un fenómeno frecuente en otras sociedades del Tercer Mundo (véase Martín-Baró, 2003 y Ferro, 2003) y va unido a la afirmación de las cualidades y características propias de los pueblos indígenas (Bello, 2004).

\section{CONCLUSIONES}

En resumen, los resultados de este estudio ofrecen una imagen de contraste acerca de los peruanos. Se los ve como un pueblo creativo y laborioso, pero al mismo tiempo con una autoestima endeble y proclive a la corrupción, y también al conformismo. Mientras que las cualidades se ven como el resultado del esfuerzo de los propios habitantes de este país por superarse, las características de acomplejamiento y de corrupción se consideran como influidas por la herencia colonial en la historia del Perú.

Esto puede observarse en los resultados del presente estudio. La imagen del peruano como pacífico y hasta abúlico, predominante hasta fines de los 1970, ha sido abiertamente cuestionada por la presencia de Sendero Luminoso y por la violencia cotidiana que se vive en el país, y la pasividad del peruano ha sido dejada de lado para verlo más bien como alguien capaz de desarrollar conductas proactivas y emprendedoras.

Pero al lado de estos cambios en la percepción del peruano también se han producido otros: predomina hoy una clara y alarmante imagen del peruano como alguien que no tiene convicciones éticas muy sólidas y que, por tanto, puede ser proclive a actos de corrupción.

La atribución de una mayor influencia de la herencia colonial en los defectos de los peruanos guarda correspondencia, por último, con la imagen poco positiva que España y los españoles tienen en los países andinos, especialmente en el Perú y Bolivia (León et al., 2008).

Sería de interés explorar cómo cada una de las cualidades y defectos atribuidos a los peruanos en general son valorados según que esos peruanos sean habitantes de la Costa, la Sierra y la Selva.

Esas tres regiones históricas del Perú han tenido un desarrollo diferente y en el imaginario popular se suele atribuir a los habitantes de cada una de ellas diferentes características psicológicas, cualidades y defectos. Estudias esas atribuciones permitiría tener una visión 
más diferenciada de las creencias y suposiciones acerca de la realidad subjetiva de los habitantes del Perú, un país multiétnico y fracturado por grandes brechas lingüísticas, económicas y de género (López Jiménez, 1997).

\section{REFERENCIAS BIBLIOGRÁFICAS}

1. Agenda: Perú (2000). Perú: agenda y estrategia para el siglo 21. Lima.

2. Alarcón, R. (2009). Psicología de la felicidad. Lima: Universidad Ricardo Palma.

3. Basadre, J. (1931/1987). Perú, problema y posibilidad. Lima: Studium.

4. Belaúnde, V. A. (1931/1991). La realidad nacional. Lima: Horizonte.

5. Bello, A. (2004). Etnicidad y ciudadanía en América Latina. La acción colectiva de los pueblos indígenas. Santiago de Chile: Comisión Económica para América Latina y el Caribe (CEPAL).

6. Crabtree, J. (2004). Retrato del Perú: su historia, sus desafíos, su gente. Lima: Instituto de Estudios Peruanos.

7. De Althaus, M. (1979). Perú: identidad nacional. Lima: Centro de Estudios para el Desarrollo y la Participación.

8. De la Riva Agüero y Osma, J. (1905/2008). Carácter de la literatura del Perú independiente. Lima: Universidad Ricardo Palma.

9. Degregori, C. I., ed. (2000). No hay país más diverso. Compendio de antropología peruana. Lima: Red para el Desarrollo de las Ciencias Sociales.

10. Devés Valdés, E. (2005). Identidad latinoamericana. En: Salas Astraín, R., coord. acad., Pensamiento crítico latinoamericano. Conceptos fundamentales. Santiago, Chile, Universidad Católica Silva Henríquez, Vol. 2, 551-560.

11. Domínguez, M. (2009). El alma de la raza. Asunción: Servilibro.

12. Espinosa, A. \& Calderón Prada, A. (2009). Relaciones entre la identidad nacional y la valoración de la cultura culinaria en una muestra de jóvenes de clase media de Lima. Liberabit, 15 (1), 21-28.

13. Flores Galindo, A. (1994). Buscando un inca: Identidad y utopía en los Andes. Lima: Horizonte.

14. Fuenzalida, F. (2009). La agonía del estad.nación. Poder, raza y etnia en el Perú contemporáneo. Lima: Fondo Editorial del Congreso del Perú.

15. Garcí.Huidobro M.Auliffe, C. (1998). Tics de los chilenos. Santiago de Chile: Sudamericana.

16. González Prada, M. (2009). Nuestros indios. En: González Prada, M., Ensayos 188.1916. Lima: Universidad Ricardo Palma, 231-243 [edición, introducción y notas de Isabelle Tauzi.Castellanos; 1904].

17. Habermas, J. (1989). Identidades nacionales y postnacionales. Madrid: Tecnos. 
18. Inca Garcilaso de la Vega (160.1617/2007). Comentarios reales de los incas. Lima: Universidad Inca Garcilaso de la Vega.

19. Larraín, H. (1996). Posmodernismo e identidad latinoamericana. Escritos. Revista del Centro de Ciencias del Lenguaje, N. ${ }^{\circ} 13-14,45-74$.

20. León, R. (2002). Situaciones cotidianas anómalas y afectos negativos en el Perú. En: Revista de Psicología, 20, 283-319.

21. León, R. (2008). El Perú de nuestros días. Una perspectiva psicológica. En: Gonzáles, O. \& Rodríguez, M.A. (eds.), El Perú y el mundo actual. Retos del presente, Lima, Universidad Ricardo Palma, 17-62.

22. León, R. (2009). ¿Cómo ven los universitarios el Perú? Un estudio por género, autoasignación racial y autoasignación socioeconómica. Universidad (Lima, Perú), N. ${ }^{\circ} 15,21-57$.

23. León, R. (2010). La escena primaria en el Perú. Imágenes sociales de Atahualpa, Pizarro, Huáscar y Almagro. Lima: Universidad Ricardo Palma.

24. León, R.; Ahlborn, B. \& Villanueva, J. (2008). España y el Perú. ¿Cómo valoramos los peruanos la herencia colonial? Lima: Universidad Ricardo Palma.

25. León, R. \& Martell, E. (1994). Valoración de conductas verbales y no verbales como expresión de envidia. Revista de Psicología, 12, 191-219.

26. León, R. \& Moscoso, S. (1991). Percepción de la envidia en el Perú en un grupo de estudiantes universitarios de Lima Metropolitana. Revista de Neuro-psiquiatría, 54.

27. Mariátegui, J. C. (1928/1992). 7 ensayos de interpretación de la realidad peruana. Lima: Amauta.

28. Martí.Baró, I. (2003). Poder, ideología y violencia. Madrid: Trotta.

29. Matos Mar, J. (1987). Desborde popular y crisis del estado. El nuevo rostro del Perú en la década de 1980. Lima: Instituto de Estudios Peruanos.

30. Mayorga, F. \& Córdova, E. (2008). El movimiento antiglobalización en Bolivia. Procesos globales e iniciativas locales en tiempo de crisis y cambio. La Paz: Plural.

31. Montoya, R. (1992). Al borde del naufragio. Democracia, violencia y problema étnico en el Perú. Lima: Sur.

32. Palacios, M. (ed.) (2009). Las independencias hispanoamericanas. Interpretaciones 200 años después. Bogotá: Norma.

33. Palma, R. (1996). Tradiciones peruanas. Madrid. Lima: Allca XX.

34. Paz, O. (1990). El laberinto de la soledad. México D.F.: Fondo de Cultura Económica.

35. Restall, M. (2004). Los siete mitos de la conquista española. Barcelona: Paidós.

36. Valcárcel, L. E. (1965). Ruta cultural del Perú. Lima: Nuevo Mundo. 


\section{APÉNDICE}

A continuación aparecen diez rasgos positivos del carácter. Valora cómo crees que se dan en el peruano promedio de hoy, y cómo crees que la presencia de ese rasgo se debe al hecho de haber sido colonia de España.

0: muy bajo, 1: bajo, 2: normal, 3: alto, 4: muy alto

En el peruano promedio Se debe a España

1. Trabajador

2. Honesto

3. Emprendedor

4. Ambicioso

5. Ahorrativo

6. Solidario

7. Creativo

8. Ordenado

9. Orgulloso

10. Planificador

Ahora hay diez rasgos negativos del carácter. Valora cómo crees que se dan en el peruano promedio de hoy, y cómo crees que la presencia de ese rasgo se debe al hecho de haber sido colonia de España (0: muy bajo, 1: bajo, 2: normal, 3: alto, 4: muy alto).

En el peruano promedio Se debe a España

1. Flojo

2. Corrupto

3. Conformista

4. Fatalista

5. Gastador

6. Individualista

7. Pasivo

8. Envidioso

9. Acomplejado

10. Hablador 